\author{
Abstracta Iranica \\ Abstracta Iranica Revue bibliographique pour le domaine irano-aryen \\ Volume 34-35-36 | 2017 \\ Comptes rendus des publications de 2011-2013
}

\title{
Michal Bar-Asher Siegal. Early Christian Monastic Literature and the Babylonian Talmud
}

Florence Jullien

\section{(2) OpenEdition}

Journals

Édition électronique

URL : http://journals.openedition.org/abstractairanica/42389

DOI : 10.4000/abstractairanica.42389

ISSN : 1961-960X

Éditeur :

CNRS (UMR 7528 Mondes iraniens et indiens), Éditions de l'IFRI

Référence électronique

Florence Jullien, « Michal Bar-Asher Siegal. Early Christian Monastic Literature and the Babylonian Talmud », Abstracta Iranica [En ligne], Volume 34-35-36 | 2017, document 25, mis en ligne le 30 juillet 2017, consulté le 01 octobre 2020. URL : http://journals.openedition.org/abstractairanica/42389; DOI : https://doi.org/10.4000/abstractairanica.42389

Ce document a été généré automatiquement le 1 octobre 2020.

Tous droits réservés 


\title{
Michal Bar-Asher Siegal. Early Christian Monastic Literature and the Babylonian Talmud
}

\author{
Florence Jullien
}

\section{RÉFÉRENCE}

Michal Bar-Asher Siegal. Early Christian Monastic Literature and the Babylonian Talmud. Cambridge, Cambridge University Press, 2013, VIII-265 p. (Divinations: Rereading Late Ancient Religion series) ISBN : 978-1-107-02301-7. € 67 ; \$ 103

1 Ce travail est le fruit d'une thèse de doctorat soutenue en 2010 à l'University de Yale. Le sujet est novateur et à la croisée des études sur le judaïsme ancien et le christianisme à l'époque tardo-antique : l'analyse des interactions entre les rédacteurs du Talmud de Babylone et leurs "voisins" chrétiens, spécialement dans les milieux monastiques. Une discussion introductive (chap. I, "Christianity in the Babylonian Talmud») pose les jalons de la réflexion à travers une histoire de la recherche en particulier les travaux de Peter Brown sur le saint homme, et leur impact sur la recherche ultérieure (p. 1-34). L'A. y expose aussi des considérations méthodologiques sur l'analyse littéraire comparative qu'elle se propose de conduire. Dans les premiers chapitres une contextualisation historique permet de rendre compte des échanges culturels entre communautés religieuses dans l'empire sassanide. L'A. souligne l'importance du courant monastique au moment de la rédaction du TB (située entre $\mathrm{V}^{\mathrm{e}}$ et VIII ${ }^{\mathrm{e}} \mathrm{s}$. selon les chercheurs), et les relations possibles entre moines et rabbins à cette époque (chap. II, section « Monasticism in Persia »). La présentation reste cependant très généraliste, les mises en contexte accumulent les citations en "mosaïque" tirées de travaux des chercheurs et ne s'appuient pas sur les sources primaires qui ne sont pas citées. Certaines thématiques sont abordées trop brièvement et auraient mérité d'être mieux problématisées dans le prisme des relations entre communautés juives et chrétiennes, qui constitue la perspective originale de ce livre. Ainsi, une cartographie analytique des 
centres d'enseignement chrétiens et juifs par exemple aurait été intéressante à étudier (p. 55 : brève énumération; p. 53 : l'A. évoque précisément l'école de Séleucie où étudia le catholicos Mār Abba et suggère un parallèle avec la Mahoza de la littérature rabbinique où des yeshivot étaient localisées). De même une éventuelle propagande missionnaire chrétienne auprès des communautés juives aurait pu être développée, même sur le temps long, comme le suggèrent certains textes (voir par exemple l'histoire d"Abdulmasīh de Singar qu'il faudrait sans doute situer, à la suite de J. M. Fiey, en 598) ; la littérature chrétienne du IV $\mathrm{e}$ s. produite dans la région d'Édesse et plus généralement en Syrie, que l'A. aborde dans la section " Jews and Christians in the Persian Empire " (p. 55-62), est aussi - il faut le rappeler - le fruit de relectures orientées vers un lectorat juif, et témoigne d'un souci d'adaptation et d'assimilation des traditions juives, ce qui en explique les aspects judaïsants, comme l'a bien montré $\mathrm{H}$. J. W. Drijvers à propos de la Doctrine d'Addaï. Les éléments de réflexion présentés dans cette section ont déjà été abordés dans le chap. I, à travers d'autres exemples. Les traditions populaires, spécialement les pratiques magiques, ont pu renforcer les relations entre communautés religieuses, ce qui est souligné à juste titre.

2 Au cœur de cette démonstration, l'A. s'intéresse à l'importance des interactions littéraires entre communautés juives et chrétiennes, ce dont rend compte spécialement la rédaction du Talmud babylonien. Cette contribution met surtout en valeur l'héritage monastique syriaque parmi les apports exogènes qui contribuèrent à former le TB. La confrontation de certains passages avec les Apophtègmes éclaire bien l'intégration et la réappropriation de certaines thématiques, mais aussi de séquences narratives, attestant par ailleurs une influence formelle et stylistique sur les modes de rédaction du TB : ces analogies portent sur l'ascèse et ses dangers, la vie de prière, les dérives morales et leurs vertus contraires, le rapport aux Écritures (chap. III). Quelques exemples de motifs narratifs partagés ou parallèles sont donnés en exemple (chap. IV) : image du poisson hors de l'eau pour décrire l'atrophie spirituelle du croyant négligent ; thèmes pris au registre de l'éducation ; figures-types comme le jeune ignorant, le berger, l'homme simple et vertueux, etc. On sait que les écrits ascétiques d'Égypte (Apophtegmata Patrum, Vie d'Antoine par Athanase, Histoire lausiaque de Pallade, ou encore les œuvres d'Évagre le Pontique), rapidement traduits dans les principales langues des chrétiens d'Orient - on connaît des versions en arménien, en syriaque, en sogdien ou encore en géorgien - constituaient le socle de la formation dans les monastères syriaques de l'empire perse mais aussi en territoire byzantin. Les points de contact littéraires présentés ici offrent une preuve supplémentaire de la circulation de ces textes monastiques dans les milieux juifs, dans un contexte d'enrichissement constructif et non polémique de traditions. Une bibliographie étoffée est suivie d'un index utile des sujets, sources et auteurs. 


\section{AUTEURS}

\section{FLORENCE JULLIEN}

CNRS, Mondes iranien et indien 